\section{Banach in Kraków: A Case Reopened}

Danuta Ciesielska and Krzysztof Ciesielski

Does your hometown have any mathematical tourist

attractions such as statues, plaques, graves, the café

where the famous conjecture was made, the desk where

the famous initials are scratched, birthplaces, houses, or memorials? Have you encountered a mathematical sight

on your travels? If so, we invite you to submit an essay to

this column. Be sure to include a picture, a description

of its mathematical significance, and either a map or

directions so that others may follow in your tracks.

> Submissions should be uploaded to http://tmin.edmgr.com or to be sent directly to Dirk Huylebrouck, huylebrouck@gmail.com
S tefan Banach (1892-1945) is regarded as the best Polish mathematician in history. Almost all his mathematical results were obtained in Lvov, where he worked after 1920. Nevertheless, he spent his youth in Kraków, and there in 1919 he took part in an event that was very important to Polish mathematics.

In 1795 Poland lost its independence. Regaining it at the end of World War I created favourable conditions for the establishment of national learned societies. On April 2, 1919, a special meeting of mathematicians was convened in Kraków in the building at No. 12 St. Anne Street that housed the Mathematics Seminar of the Jagiellonian University (Fig. 1): Kraków mathematicians had decided to establish a Mathematical Society in their town to advance pure and applied mathematics. Sixteen mathematicians took part in the session; all of them became founding members of the society, and Stefan Banach was among them. Stanisław Zaremba was elected the President of the Society. In the following months, mathematicians from other academic centres, including Warsaw, joined in, among them Wacław Sierpiński, Zygmunt Janiszewski, and Stefan Mazurkiewicz (in September 1919). On April 21, 1920, the society officially changed its name to the Polish Mathematical Society; its statutes recognise the constitution meeting in Kraków in April 1919 as the date of its foundation.

The names of mathematicians who set up the society, their occupations, and addresses are listed in the minutes of the April 2, 1919, meeting (Figs. 2, 3). Of the sixteen founders of the society, six were academic staff, seven taught in secondary schools (called in Polish gymnasia), and one was an engineer; the occupations of the remaining two, including Banach, were not mentioned, as they were unemployed. Isn't it surprising

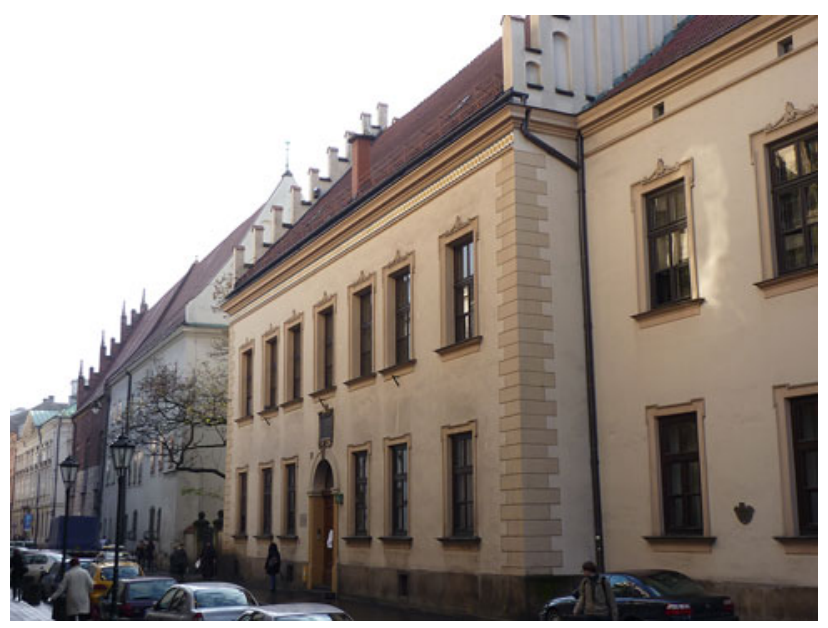

Figure I. The house at St. Anne Street where the Polish Mathematical Society was founded. 


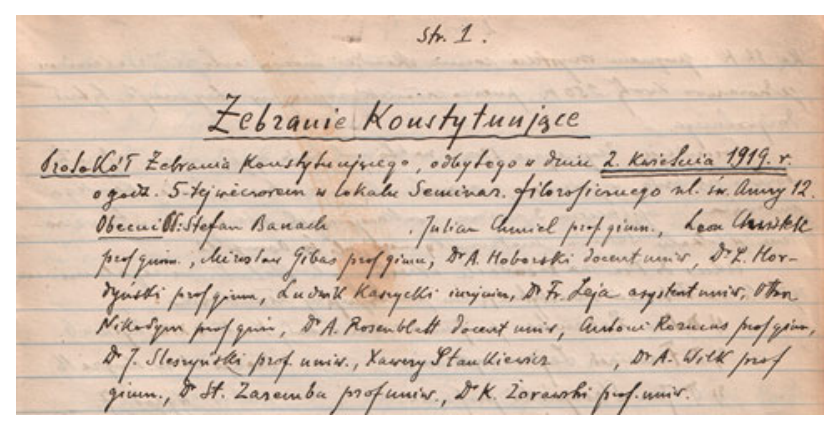

Figure 2. The attendance list on the first page of the minutes of the constituting session.

that Banach, although 27 years old then, was not a faculty member yet?

Recall the famous story about "the discovery" of Banach in Kraków's Planty Park in 1916. Banach had graduated from a gymnasium in 1910 and decided to study engineering. There was no technical university in Kraków, so he moved to Lvov. When World War I began, Banach gave up his studies and came back to Kraków. He developed his mathematical knowledge by self-study. He also attended some mathematical lectures at the Jagiellonian University. In 1916, Hugo Steinhaus, who had been staying in Kraków for some time, was taking an evening walk in the Planty Gardens, when he unexpectedly heard someone utter the words "Lebesgue integral." It turned out that two young men, Stefan Banach and Otto Nikodym, were sitting on a bench and talking about modern mathematics. Steinhaus joined the conversation. Banach and Nikodym told him that they often discussed mathematics and that they were frequently joined in their debates by a third friend, Witold Wilkosz. In the ensuing conversation, Steinhaus told them about a problem he had

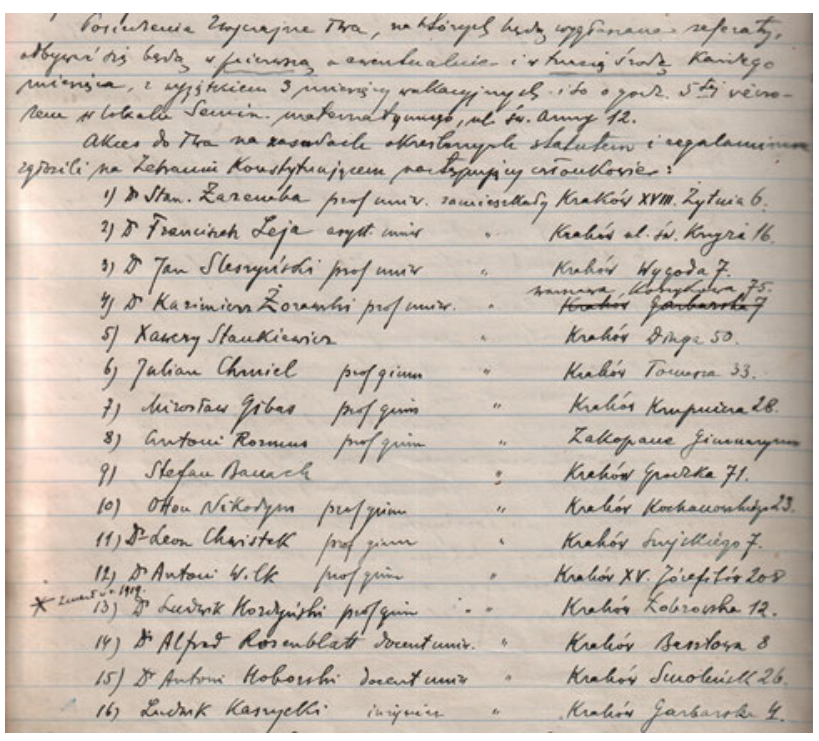

Figure 3. The list of the founders of the Polish Mathematical Society (a fragment of the second page of the minutes, Banach is in position 9, and Nikodym is in position 10).

been working on, and after a few days Banach brought him a solution. This result was published 2 years later in a joint paper by Banach and Steinhaus in the Bulletin of the Academy of Arts and Sciences in Krakow ([1]); it was Banach's first research paper. Steinhaus would often say later that his greatest mathematical discovery was Banach.

We have been asked on several occasions: where precisely was this bench where Steinhaus encountered Banach? The Planty Gardens is a large park of about 52 acres ( 21 hectares) surrounding the historical centre of Kraków. The meeting could have happened in many different places. In his memoirs

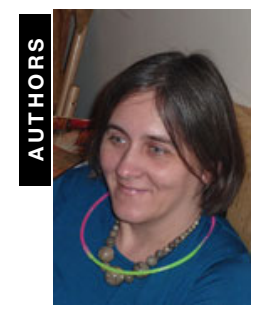

DANUTA CIESIELSKA AND KRZYSZTOF CIESIELSKI obtained their Ph.D. degrees from the Jagiellonian University in Kraków. Danuta's specialty is complex analytic geometry and history of mathematics, and Krzysztof's is topological dynamical systems. In addition to "classical" academic activities, they work very actively in popularizing mathematics. They write popular articles and books, present many special lectures to school students and teachers, and work actively in the organization and juries of several mathematical competitions. Danuta is a member of the Polish Academy of Arts and Sciences Commission on the Evaluation of Textbooks.

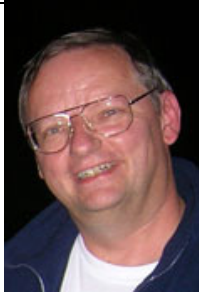
Krzysztof is a correspondent for The Mathematical Intelligencer and a member of the Raising Public Awareness of Mathematics Committee of the European Mathematical Society. They married 25 years ago. They have two children, now students at the Jagiellonian University; Adam studies astrophysics, Barbara mathematics. All of them in their free time enjoy walking in the mountains.

Mathematics Institute

Pedagogical University in Kraków

Podchorążych 2, 30-084 Kraków

Poland

e-mail: smciesie@cyfronet.krakow.pl
Faculty of Mathematics and Computer

Science,

Mathematics Institute

Jagiellonian University

Łojasiewicza 6, 30-348 Kraków

Poland

e-mail: Krzysztof.Ciesielski@im.uj.edu.pl 
and articles about Banach, Steinhaus only writes that it was in the Planty Gardens.

We tried to analyse the problem and came to a conclusion. In our opinion, it is almost certain that this famous bench stood in the extreme part of Planty Gardens, between Wawel Castle and Franciszkańska Street (Fig. 4), known as the Wawel Garden (see the map, Fig. 5). Why?

It is an established fact that Banach, Wilkosz, and Nikodym used to walk and talk about mathematics in the evenings. They would accompany one of their group to his home, but the person being seen home would very frequently not take leave of his colleagues, but continue to walk back with them. The best route from Nikodym's house to Banach's place led through a shortcut along the street at the foot of Wawel Castle after passing some alleys at the far end of Planty Gardens. So, the most probable solution to the "bench problem" is as follows: There are two possibilities. The first is that Banach and Nikodym went all the way to Banach's house, but as the talk was interesting, they turned back, quickly entered Planty Gardens, and sat on a bench. The second is that Banach and Nikodym were on the way to Banach's dwelling, but their talk was so fascinating that when they approached the edge of the park, they decided to sit down and continue the discussion. The location of their respective homes definitely suggests either the part of Planty Gardens adjacent to Wawel Castle, or a section in front of Collegium Novum building. However, in our opinion the second hypothesis should be ruled out. First, the latter place was further away from Banach's home and it is more probable that the friends sat closer to the end of the park. Second and more important, Collegium Novum - the main university building - is a very characteristic landmark, so it is almost sure that if Steinhaus had met them there, he would have mentioned it.

Otto Nikodym (1887-1974), who was to become a renowned mathematician (remembered, among other things, for the result known today as the Radon-Nikodym Theorem), was also among the founders of the Polish Mathematical Society; his name appears on the list in Figure 3. Note that he was then not a member of an academic staff, but a gymnasium teacher. This was not unusual. After graduating from the university, mathematicians frequently started teaching at

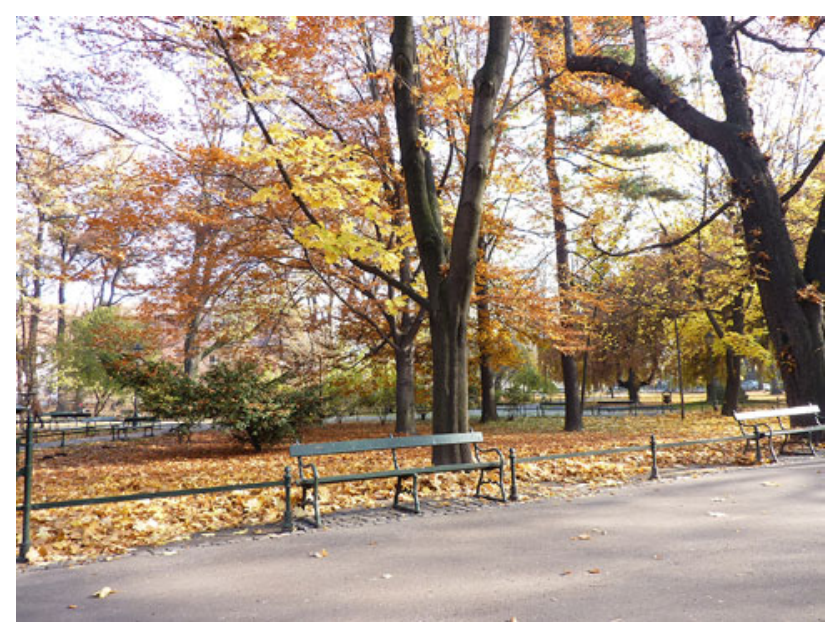

Figure 4. The benches in Planty Gardens (in the probable location where Steinhaus met Banach in 1916).

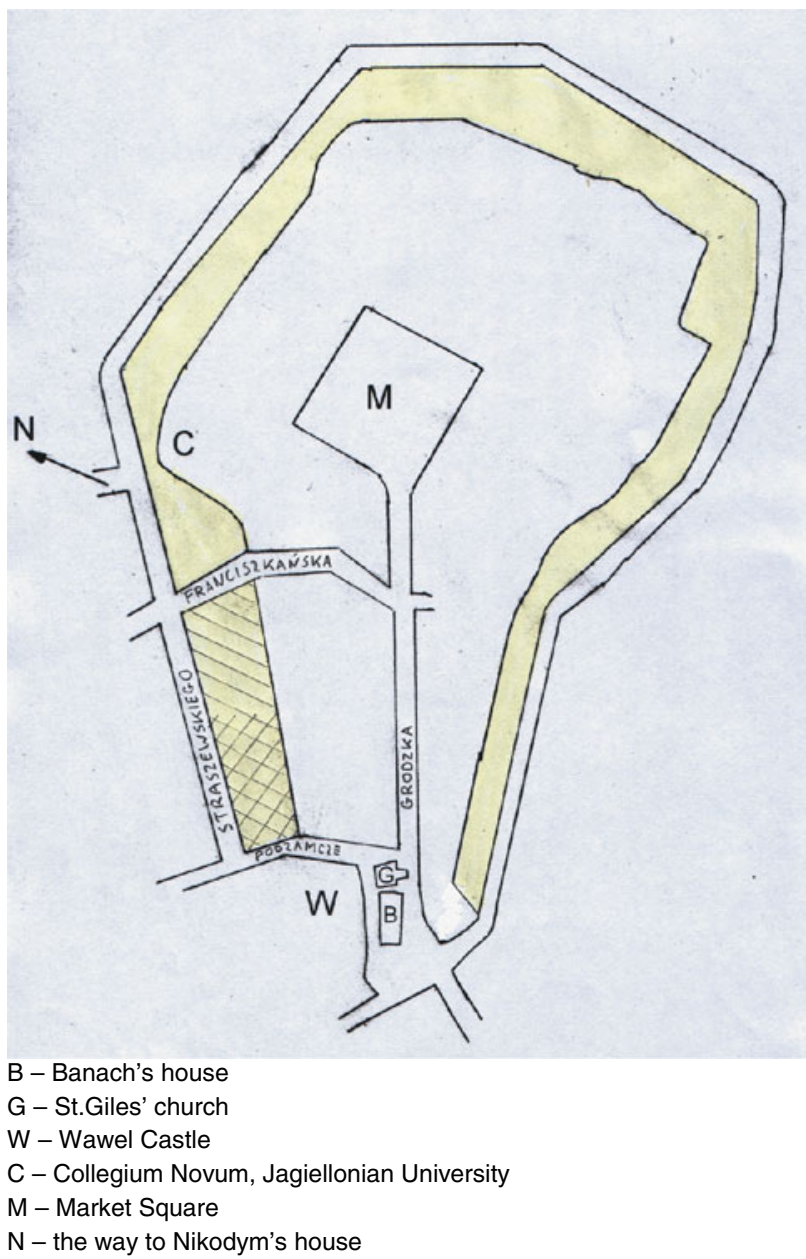

- Planty Park

- the area of the park, where probably was Banach's bench

- the area of the park, where most probably was Banach's bench

Figure 5. The map of Kraków city centre with the probable location of the bench.

schools and only after some years joined the faculty. Later Nikodym received his Ph.D. from Warsaw University. After World War II he moved to the USA and became a professor at Kenyon College in Gambier, Ohio.

The third man, Witold Wilkosz (1891-1941), was a classmate of Banach in the gymnasium. He obtained a Ph.D. from the Jagiellonian University in 1918 and later was appointed to a chair there. Wilkosz had a very broad range of mathematical interests and profound knowledge. He obtained his main results in the fields of the foundations of mathematics and mathematical analysis. Both Nikodym and Wilkosz were invited speakers at the International Congresses of Mathematicians: Nikodym in Bologna in 1928, Wilkosz in Zurich in 1932. Banach was a plenary speaker at the ICM 1936 in Oslo and an invited speaker in 1928. For more information on Kraków's mathematics and Banach's achievements, see [3], [4], and [5].

In 1999, after long-standing efforts of the Kraków Branch of the Polish Mathematical Society, a Banach monument was unveiled in Kraków (details about this monument and other places in Kraków connected with Banach can be found in [2]). 


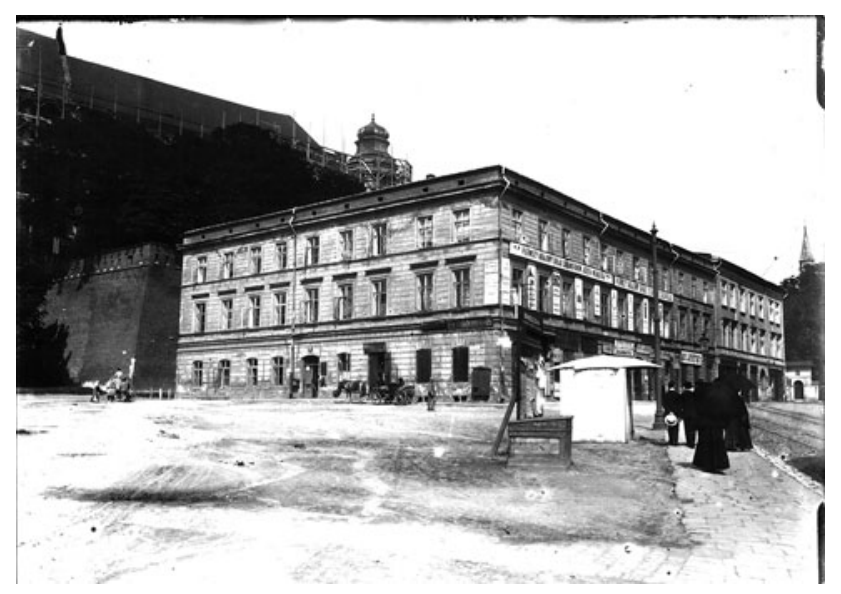

Figure 6. The house at Grodzka Street 71 where Banach lived (beginning of the 20th century). (Courtesy of the Institute of Art of the Polish Academy of Sciences.)

Unfortunately the idea of placing the statue in Planty Gardens, where Banach was "discovered," was not accepted by the city authorities, and the monument was erected in front of the then seat of the Mathematics Institute of the Jagiellonian University. However, we are now trying to have a commemorative plaque attached to one of the benches in Planty Gardens, and there is a chance that this idea will be put into practice.

Let us correct here one detail from [2]. It was claimed there that Banach had lived at the end of Grodzka Street, in building No. 71 at the foot of Wawel Castle. The street shown in the photograph included was indeed Grodzka Street, where Banach had walked each day. However, the last house in Grodzka Street shown in the photo was incorrectly described as Banach's residence, although Banach was resident in the last house on the street!

We found the first clue about the misunderstanding as we came across a list of Grodzka Street buildings before World War I in the National Archives in Kraków. Nowadays, the last house has the number 65, but we learned in the Archives that the houses in Grodzka Street had been renumbered. The photograph showed the last house in Grodzka Street, behind which there was only a small church, dedicated to St. Giles. It is hard to imagine any building further down the street, as this is where the street ends.

Nevertheless, we managed to obtain a picture of Grodzka Street taken shortly before the outbreak of World War I (Fig. 6), which shows that there indeed was another building behind the church! That was the real house No. 71 where Banach lived, a large structure dating from the second half of the 19th century. During World War II it was destroyed, and now in its place is a small square abutting on Podzamcze Street (Fig. 7).

The documentation obtained from the Archives may not furnish conclusive evidence about Banach's place of residence, due to some confusion created by the renumbering of houses. However, his address is confirmed independently by other sources, especially by the aforementioned list of the signatories of the Polish Mathematical Society in the minutes of the constituting session.

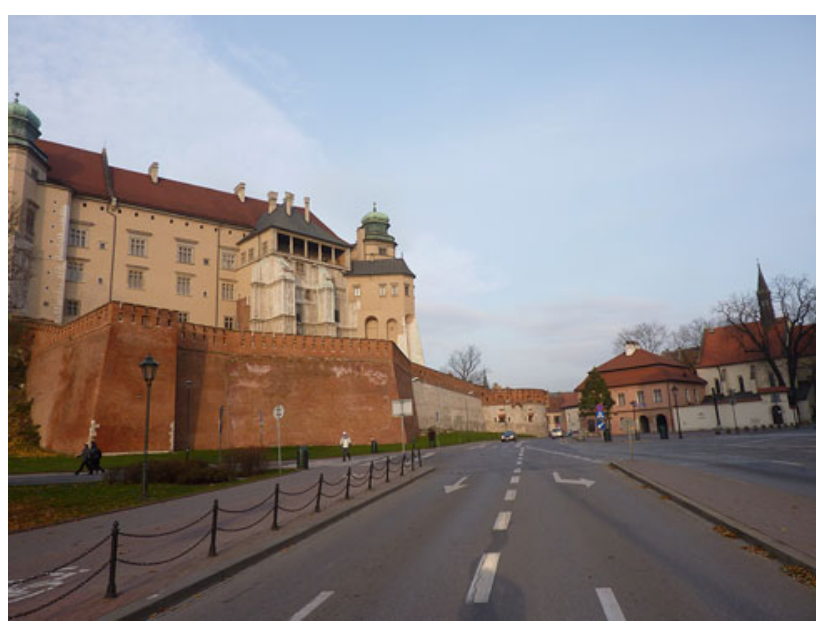

Figure 7. Present view of the place where Banach's house was 100 years earlier (picture taken from the same location as in the previous photo).

Let us finish this story with the presentation of some interesting pictures including a historical one and others from modern times.

In September 1929 the First Congress of Mathematicians of the Slavic Countries was held in Warsaw. About 70 mathematicians from Poland, Bulgaria, Yugoslavia, and Czechoslovakia participated. In the popular-science monthly Mathesis Polska (published in Poland in 1926-1938), a special supplement was added to the issue $7 / 8$ of 1929 . It contained a collection of caricatures of participants in the Congress, drawn by the Polish

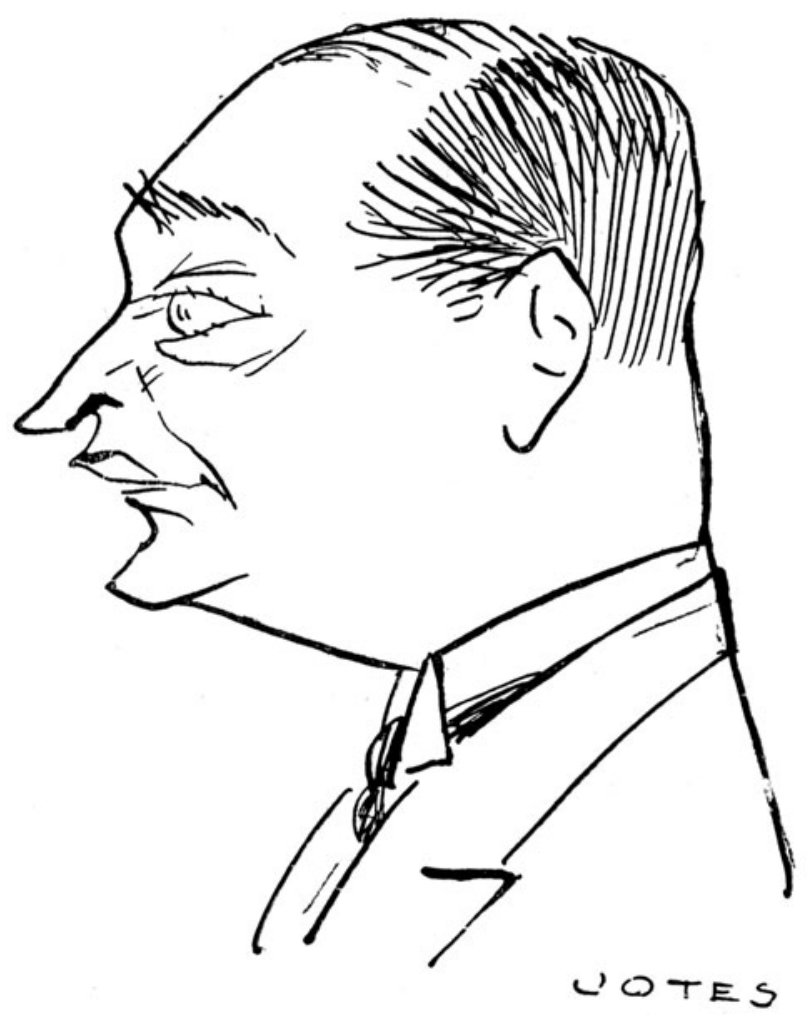

Figure 8. The caricature of Banach by Jotes (from Mathesis Polska, 1929). 

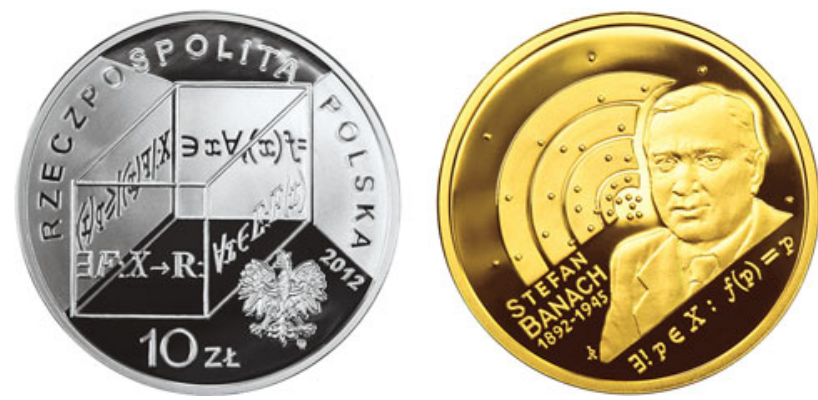

Figure 9. The obverse of the 10 PLN coin and the reverse of the 200 PLN coin. (Courtesy of the National Bank of Poland and Robert Kotowicz.)

cartoonist Jerzy Szwajcer, who signed his works as "Jotes." Among the mathematicians thus portrayed was Banach (Fig. 8). To the best of our knowledge, this illustration was never republished after World War II. The journal Mathesis Polska is now available only in very few libraries.

The year 2012 marked the 120th anniversary of Banach's birth. In the same year, the Sixth European Congress of Mathematics took place in Kraków. On these occasions the National Bank of Poland issued special collector coins (Fig. 9). Three kinds of coins were issued: a 2 Polish zloty (PLN) piece struck in "Nordic gold," a silver 10 PLN, and a gold 200 PLN. Robert Kotowicz designed them. The reverse of each coin portrays Banach, in each case with a different mathematical addition. In the 2 PLN coin there is a graph of one-dimensional linear mapping and the inequality $\|T(x)\| \leq\|T\| \cdot\|x\|$; the obverse is the same as in other Polish 2 PLN coins. On the obverse of the 10 PLN coin is a cube with the conclusion of the
Hahn-Banach theorem written on its sides; on the reverse is the inequality $\|S \circ T\| \leq\|S\| \circ\|T\|$. On the 200 PLN gold coin, the obverse and the reverse are connected with the Banach Fixed Point theorem. These coins were available for purchase, but the price of the silver and gold ones was much higher than the face value. For example, the gold coin cost 2730 PLN (about 900 USD). A total of 45,000 silver coins and 4,000 gold coins were issued. Expensive as they were, the coins were met with keen interest by many mathematicians, who wanted to include them in their collections of mathematical curios.

\section{OPEN ACCESS}

This article is distributed under the terms of the Creative Commons Attribution License which permits any use, distribution, and reproduction in any medium, provided the original author(s) and the source are credited.

\section{REFERENCES}

[1] S. Banach, H. Steinhaus, Sur la convergence en moyenne de séries de Fourier, Bull. Int. de l'Acad. Sciences de Cracovie, Séries A, Sciences Mathématiques (1918), 87-96.

[2] D. Ciesielska, K. Ciesielski, Stefan Banach remembered in Kraków, Math. Intelligencer 30 (2008), no. 4, 31-35.

[3] K. Ciesielski, Z. Pogoda, On mathematics in Kraków through centuries, Wiadomości Matematyczne 48 (2012), no. 2, 313-324 (reprinted in EMS Newsletter, no. 86).

[4] E. Jakimowicz, A. Miranowicz (eds.), Stefan Banach: remarkable life, brilliant mathematics, Gdańsk University Press, 2010.

[5] R. Kałuża, Through a reporter's eyes: the Life of Stefan Banach, Birkhäuser, 1996. 